\section{In vitro Propagation of Laelia albida (Orchidaceae) for Conservation and Ornamental Purposes in Mexico}

\author{
Leticia Santos-Hernández, Martha Martínez-García, Jorge E. Campos, \\ and Ernesto Aguirre-León ${ }^{1}$ \\ Unidad de Biología, Tecnología y Prototipos, Facultad de Estudios Superiores \\ Iztacala, Universidad Nacional Autónoma de México, Av. de los Barrios \\ $N^{\circ}$ 1, Los Reyes Iztacala, Tlalnepantla, Apdo. Postal 314, Edo. Méx. C.P. \\ 54000,Mexico
}

Additional index words. Laelia albida, seed germination, orchid conservation, seed storage, micropropagation

\begin{abstract}
The orchid Laelia albida is an important cultural and religious plant resource of the Tehuacan-Cuicatlan Valley Biosphere Reserve in south-central Mexico. It is gradually becoming scarce due to overcollecting and habitat perturbation. For this reason, and for preservation purposes, the aim of the present work was to obtain the conditions to successfully propagate this species, through the use of mature seeds stored at $4{ }^{\circ} \mathrm{C}$, and basal buds following in vitro techniques. Seeds with different storage periods (lot 1 and lot 2) were analyzed for seed viability as determined by the TTC method, germination percentage and germination index were analyzed on a monthly basis for 11 months on two Knudson C (K-4003, K-4128; Sigma). Seedlings were initially grown on the same culture media variants, but 30 days later they needed to be supplemented with potato starch $\left(20 \mathrm{~g} \cdot \mathrm{L}^{-1}\right)$. Basal buds were cultured on Knudson C containing nine BAP and NAA combinations two of which were also supplemented with potato $\operatorname{starch}\left(20 \mathrm{~g} \cdot \mathrm{L}^{-1}\right)$ and coconut water $(10 \%)$. Seed viability ranged from $78 \%$ to $98 \%$ throughout the 11 months and germination percentage was $70 \%$ to $90 \%$ without significant differences between the two lots. K-4003, either alone or supplemented with potato starch, was the best culture medium used to achieve all the development stages as well as seedlings with rhizoids. Bud proliferation was also successful on K-4003 added with BAP, NAA, potato starch and coconut water. The BAP $(7.4 \mu \mathrm{M})$ and NAA $(5.3 \mu \mathrm{M})$ combination promoted shoots and protocorm-like bodies (PLB). The results obtained with basal buds, make its preservation through in vitro culture possible and give the possibility to obtain available plantlets for its cultivation in regional nurseries. Storage conditions tested here may be useful for seed bank management for this species. Chemical names used: 6-benzylaminopurine (BAP), 1-naphthaleneacetic acid (NAA).
\end{abstract}

Since its discovery in 1832 in Oaxaca, Mexico, Laelia albida is the best known Laelia orchid, due to its attractive white flowers, in contrast with the rose flowers of the other known Laelia species. This species is endemic to Mexico, distributed in an enormous territory that includes the Sierra Madre Occidental, the Sierra Madre del Sur and the Tehuacan-Cuicatlan Valley. It usually grows on trees, but it also has been found on rocks. Plants grow asexually forming big colonies if not disturbed, and flower from September to December. Several color varieties have been described (Halbinger and Soto, 1997). One of L. albida's natural distribution areas is the Zapotitlan Salinas Valley, within the Tehuacan-Cuicatlan Valley. The plant is commonly propagated in the

Received for publication 12 Mar. 2004. Accepted for publication 2 Oct. 2004. We thank the people and local governments of six communities of the Tehuacan-Cuicatlan Valley for their guidance and help in the field, $V$. Chavez, J.L. Cabrera, E. López, and two anonymous reviewers for comments on the manuscript. This work was supported by grants from UNAM-DGAPA-PAPIIT IN220599 and PAPCA-2003.

${ }^{1}$ To whom reprint request should be addressed; e-mail eall@servidor.unam.mx. towns close to the natural locations by division of semi-cultivated and collected adult plants (pseudobulbs). A traditional practice is the use of the cut flowers of this species in religious festivities each November. Deforestation, grazing, and desertification are other factors contributing to the wild populations reduction, as a consequence, a decrease on its genetic variability has been detected, representing a pressure on the sexual reproduction of the wild and semi-cultivated populations (SantosHernández, 2002). Moreover, seeds obtained from semi-cultivated plants were found to be sterile in some cases. Although L. albida is a worldwide popular orchid, due to cultivation and production of interesting hybrids, its ecology, genetic variation, and physiology remain to be discovered. The purpose of the present study was to obtain a method for in vitro propagation from seeds and basal buds of $L$. albida, aiming to ex situ conservation through cultivation, which should help increase its availability among local inhabitants.

\section{Material and Methods}

Plant material. Seeds and basal buds were collected from plants of the Zapotitlan Salinas Valley, within the Tehuacan-Cuicatlan Valley. Two mature seed lots were prepared by air dry for seven days and kept in small regular paper envelopes, before their storage in a cold room at $4{ }^{\circ} \mathrm{C}$ in closed glass containers. Seed viability and germination analysis of the two stored seed lots were performed on a monthly basis for 11 months. One seed lot was 1 year old (lot 1 ) and the other was 2 years old (lot 2).

Seed viability. Viability was evaluated on 100 seeds from each lot using 2-3-5 triphenyl tetrazolium chloride (TTC) at $1 \%$ according to van Waes and Debergh (1986) with the following adaptation. Seeds $(10 \mathrm{mg})$ were pretreated through immersion in distilled water for $24 \mathrm{~h}$ at room temperature and placed in vials with $1 \mathrm{~mL}$ TTC solution in darkness at $30{ }^{\circ} \mathrm{C}$ for $24 \mathrm{~h}$. Seeds were examined for the color of the embryos, those completely red were considered as viable.

Seed germination. Every month (along an 11 month span) 500 seeds of each lot were evaluated for germination and for growth on the two culture media used. Two Knudson $\mathrm{C}$ variants were used (K4003 and K4128 Sigma, Co.), gelified with Gelrite $\left(2.5 \mathrm{~g} \cdot \mathrm{L}^{-1}\right)$ and autoclaved at $121^{\circ} \mathrm{C}$ for $15 \mathrm{~min}$. Seeds were disinfected by soaking and shaking in a $10 \%$ sodium hypochlorite solution for $5 \mathrm{~min}$, rinsed 3-fold with sterile distilled water and sown onto media in petri dishes. Seed cultures were maintained at $24 \pm 2{ }^{\circ} \mathrm{C}$ under a $16 / 8$-h photoperiod with $20-\mathrm{W}$ cool-white fluorescent lamps $\left(35 \mu \mathrm{mol} \cdot \mathrm{m}^{-2} \cdot \mathrm{s}^{-1}\right)$. The germination process was evaluated by constant observation under a stereoscopic microscope every $24 \mathrm{~h}$ from the time of sowing day, and seeds were classified according to Pierik et al. (1988) as follows: a) seeds containing nongerminating embryos; b) swollen germinating seeds, but not yet rupturing the seed coat; c) seeds with embryos just rupturing the seed coat; and d) seeds with embryos completely out of the seed coat. The germination percentage $(G)$ and the germination index (GI) were calculated by equations proposed in Pierik et al. (1988) as follows:

and

$$
\begin{aligned}
& G=100\left(\frac{b+c+d}{a+b+c+d}\right) \\
& G I=\frac{10(1 b+2 c+3 d)}{a+b+c+d}
\end{aligned}
$$

Results were analyzed statistically using a factorial array (days, lot, month and media) for the variable germination and germination index.

Seedlings. Germinating seeds 30 d old were transferred from the two culture media used to the same Knudson $\mathrm{C}$ variants, supplemented with $20 \mathrm{~g} \cdot \mathrm{L}^{-1}$ of potato starch. $10 \mathrm{~mL}$ of the culture media were poured onto $60 \mathrm{~mL}$ culture vessels. Development stages were identified according to Harrison and Arditti (1978) in 1) nongerminating seeds, 2 ) swollen seeds, 3 ) seeds rupturing the seed coat, 4) protocorms, 5) one leaf seedling, and 6) two leaf plantlets with root hairs. An average of 25 seedlings of each stage was evaluated.

Basal buds. Buds were disinfected in $10 \%$ sodium hypochlorite for $10 \mathrm{~min}$, rinsed 3 -fold with sterile distilled water. Bracts were 
Table 1. Appearance average time (AAT), germination percentage $(\% \mathrm{G})$, and germination index (GI) of different seed development stages ${ }^{\mathrm{z}}$ determined on two Knudson C media variants (K-4128, K-4003).

\begin{tabular}{lccccc}
\hline $\begin{array}{l}\text { Seed } \\
\text { development } \\
\text { stage }\end{array}$ & $\begin{array}{c}\text { AAT } \\
\text { (d) }\end{array}$ & $\begin{array}{c}\text { K-4128 } \\
\% \mathrm{G}\end{array}$ & K-4003 & & \\
\hline $\mathrm{a}$ & --- & 32 & $\mathrm{GI}$ & $\% \mathrm{G}$ & $\mathrm{GI}$ \\
$\mathrm{b}$ & 15 & 74 & 8.6 & 26 & 2.2 \\
$\mathrm{c}$ & 24 & 81 & 11.0 & 81 & $9.9^{*}$ \\
$\mathrm{~d}$ & 46 & 64 & 11.0 & 85 & $12.4^{*}$ \\
\hline
\end{tabular}

${ }^{2}$ Seed development stages: a) intact embryos, b) swollen embryos, c) emerging embryos, d) protocorms. "Significantly different at $P=0.001$. taken apart and treated again with 5\% and 3\% sodium hypochlorite, and finally rinsed with sterile distilled water. After disinfecting, the inoculated onto $25 \mathrm{~mL}$ of Knudson C (K-4003) culture medium added with the supplements: BAP, NAA, potato starch $\left(20 \mathrm{~g} \cdot \mathrm{L}^{-1}\right)$ and coconut water $(10 \%)$ poured onto $125 \mathrm{~mL}$ glass culture vessels, in order to provide nine treatments. Combinations of BAP/NAA in $\mu \mathrm{M}$ in each treatment were as follows: M1 $(0 / 0.55)$, M2 (0/1.0), M3 (0.74/10.0), M4 (7.4/0.056), M5 (7.4/10.0), M6 (7.4/5.5), M7 (7.4/0), M8 $\left(7.4 / 10.0+20 \mathrm{~g} \cdot \mathrm{L}^{-1}\right.$ potato $\left.\mathrm{starch}\right)$ and, M9 $(7.4 / 10.0+10 \%$ coconut water). $\mathrm{pH}$ was adjusted to 5.5 with $1 \mathrm{M} \mathrm{HCl}$ and autoclaved at $121{ }^{\circ} \mathrm{C}$ for $15 \mathrm{~min}$. Five explants were inoculated on each treatment.

\section{Results}

Seed viability. Stored seeds displayed up to $98 \%$ sD 0.447 viability for lot 1 and up to $88 \%{ }_{\mathrm{SD}} 0.836$ for lot 2 . These percentages are higher than those found by Ortíz (2001) who found a viability of $71.60 \%$ when she induced embryo coloration in L. albida by applying a pretreatment with $5 \%$ calcium hypochlorite and Tween 80 in $1 \%$ TTC for $72 \mathrm{~h}$. In the present study, only $24 \mathrm{~h}$ immersion in distilled water was necessary to imbibe the seeds, indicating that seed coat permeability is not as low as in other orchid species (Vujanovic et al., 2000).

Seed germination. The germination percentages $(\mathrm{G})$ for lot 1 were $85 \%$, and for lot $2,75 \%$ in the course of 11 months without significant differences. However, significant differences were found for $\mathrm{K}-4003$ medium $(P$ $=0.001$ ) concerning growth index (Pierik etal., 1988). As shown in Table 1 , the average time obtained on K-4003 medium for the appearance of development stages of emerging embryos (c stage) and protocorms (d stage), was 24 and 46 d respectively. However, K-4128 medium only supported a higher frequency of early a, $\mathrm{b}$ and $\mathrm{c}$ stages, even after $46 \mathrm{~d}$. The difference may be due to the element concentration in each modified formula; the K-4003 culture medium contains 2 -fold calcium nitrate molar concentration in contrast to K-4128 medium. Calcium facilitates carbohydrate and amino acid movement through plant tissues, favoring their assimilation in seeds lacking endosperm such as those of orchids. Pierik et al. (1988) have shown that a germination index value higher than 9 indicates a higher probability of developing plantlets. The germination index was found to give significant differexplant, consisting of each dissected bud, was ences between lot $1(P=0.001)$, and lot 2 . After 6 months there was a germination index decrease in lot 2 (Fig. 1) and also on viability and germination percentage, which probably are indicative of a natural aging process in these seed lots. velop after a time on the K-4003 and K-4128 media, both were supplemented with potato starch as another exogenous carbohydrate source. This gradually promoted new development stages, on day 34 for the protocorms, on day 73 for seedlings with a leaf and on day 106 , for the formation of seedlings with two leaves and root hairs (stage 6). This was in contrast to the not-enriched media in which a loss of germinating embryos occurred after $45 \mathrm{~d}$ of culture (Fig. 2). This result is slightly similar to the one obtained by Harrison and Arditti (1978) in their pioneer work with Cattleya aurantiaca, when they observed seedlings in stage 6 only when sucrose was added to the medium after $100 \mathrm{~d}$ of culture. But in our case, this stage was only reached when potato starch was added to the media with sucrose. It has been reported (Penfield and Campbell, 1990), that potato
Seedling growth. As seedlings did not de- starch contains niacin, which "enhances orchid seed germination and seed development more consistently than any other vitamin" (Arditti and Ernst, 1984) and phosphate esterified with glucose residues of amylopectin.

Bud meristems. M1 and M2 media caused a gradual elongation and enlargement to the uMBAP concentration in M6, M7, M8, and M9 media induced PLB without callus formation on the fourth week. Survival on these media oscillated from $80 \%$ to $100 \%$. Formed PLB were transplanted onto M8 and M9 media on which seedlings developed pseudobulbs and roots, producing 10 to 20 plantlets per flask after 8 months of culture. M4 to M7 media performed as initiation media whereas M8 and M9 performed as multiplication media (see Table 2). In short, M5 medium induced shoots, M6 medium induced plantlets, M7 medium induced PLB and M8 medium allowed shoot and PLB proliferation (Fig. 3d).

\section{Discussion}

Under the storage conditions used, viability and germination tests rendered values of up to $98 \%$ and $85 \%$ respectively and in vitro culture provided seedlings with root hairs after $106 \mathrm{~d}$ (stage 6). Those differences found between the viability and germination tests, could probably due to the procedure used in the biochemical test itself, but the germination test is decisive.

If conditions used here were followed, a longer preservation period in this species could probably be achieved. Although seed moisture content was not verified in L. albida seeds, the viability values observed $(98 \%$ to explants, although these did not survive. A 7.4

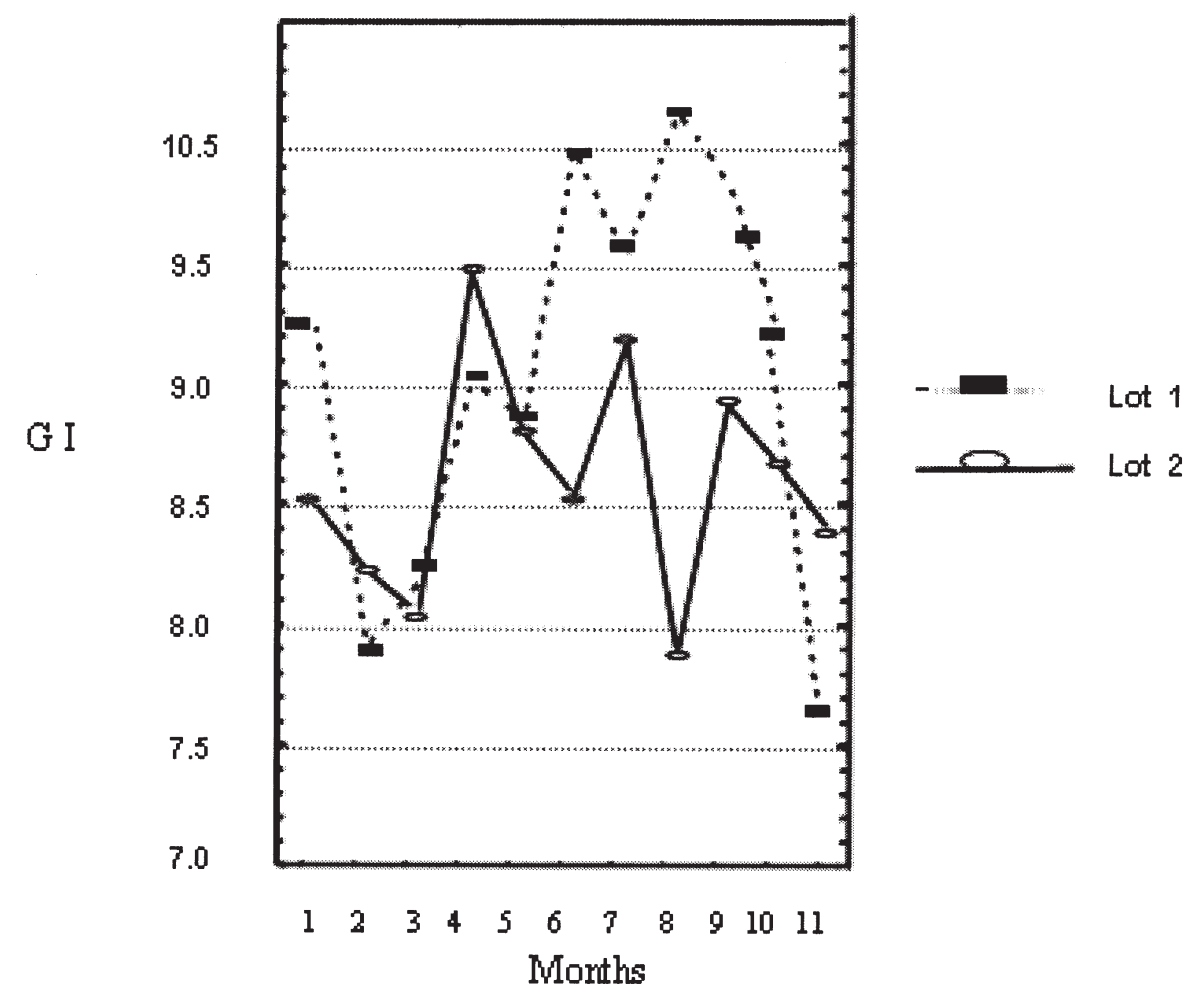

Fig. 1. Germination index (GI) in two seed lots studied (see also Table 1). 


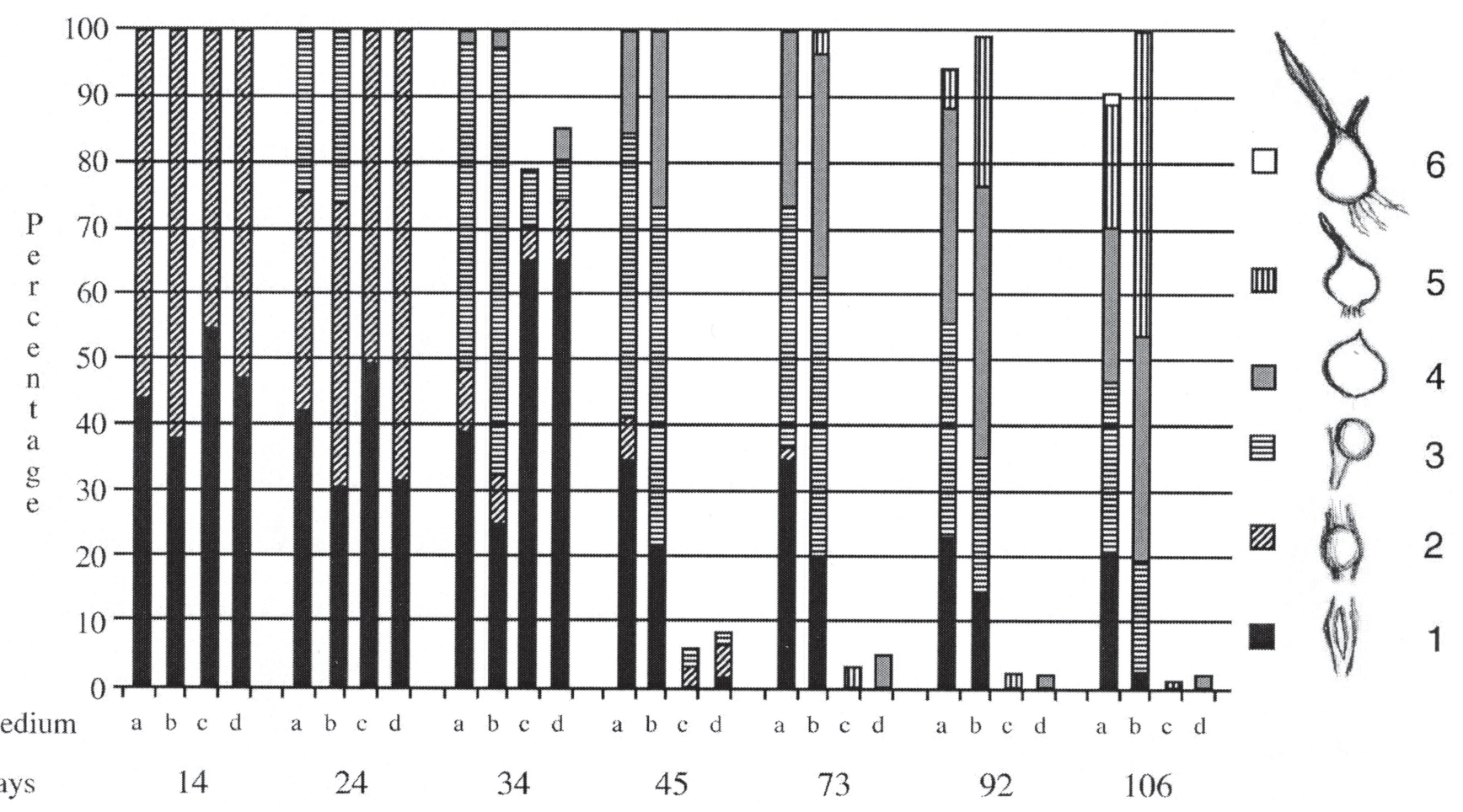

Table 2. Effects of initiation and multiplication media on the production of PLB rotted plantlets and survivorship.

\begin{tabular}{ccccc}
\hline \multicolumn{2}{c}{ Medium $^{\text {z }}$} & PLB & $\begin{array}{c}\text { Rooted } \\
\text { plantlets }\end{array}$ & $\begin{array}{c}\text { Survivorship } \\
(\%)\end{array}$ \\
\hline GM & M1 & --- & --- & -- \\
& M2 & --- & --- & -- \\
& M3 & --- & -- & 20 \\
IM & M4 & --- & 2 & 40 \\
& M5 & --- & 3 & 80 \\
& M6 & 4 & 6 & 80 \\
& M7 & 4 & 6 & 90 \\
MM & M8 & 4 & $10-20$ & 90 \\
& M9 & 5 & $10-20$ & \\
\hline
\end{tabular}

${ }^{\mathrm{z}} \mathrm{GM}=$ germination medium; IM = initiations medium; $\mathrm{MM}=$ multiplication medium

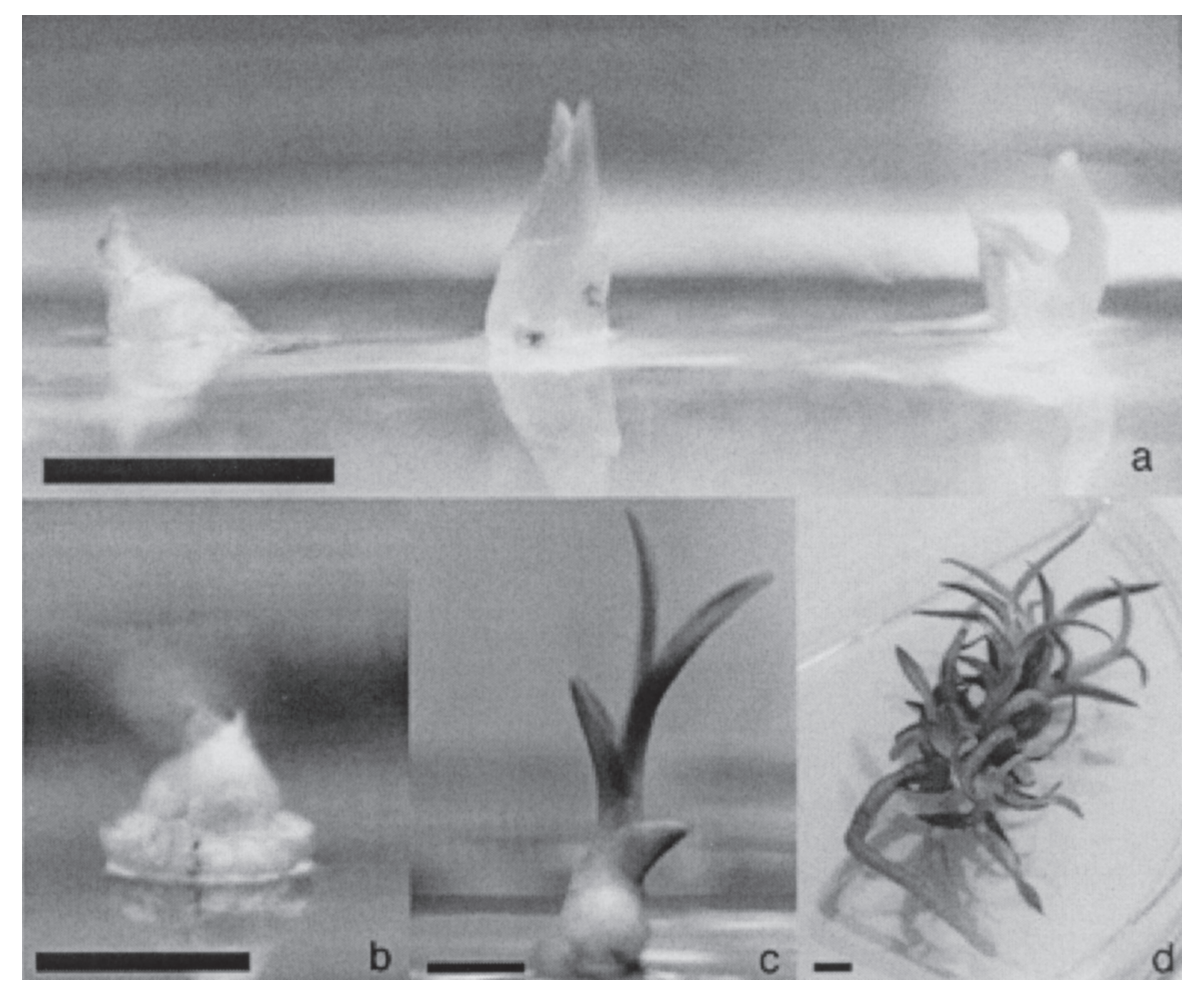

Fig. 2. Development stages of Laelia albida on four culture media: 1) nongermination seeds, 2) swollen seeds, 3) seeds rupturing the seed coat, 4) protocorms, 5) one leaf seedling and 6) two leaf plantlets with root hairs. Culture media: a $=\mathrm{KC} 4128+$ potato, $\mathrm{b}=\mathrm{KC} 4003+$ potato, $\mathrm{c}=$ C4128, d = KC4003.

$88 \%$ ) allow us to assume that seed moisture content remained within an adequate moisture range as it has been reported (Mugambi 2002; Seaton and Hailes, 1980; Seaton and Pritchard, 2003; Shoushtari et al., 1994). Linington and Pritchard (2000) explain that seed moisture content is critical for its storage. Mugambi (2002) discusses, among other factors, that moisture content of $5 \%$ to $10 \%$ increases longevity of orchid seeds stored for a long period.

In contrast with the requirements of other species, as Cattleya aurantiaca, in the present work it was found that for Laelia albida seedlings, it was of benefit to add potato starch as well as sucrose to the culture media, to improve their development.

The BAP and NAA concentration balance is important in PLB formation. A $7.4 \mu \mathrm{M}$ concentration BAP and 5.3 $\mu \mathrm{M}$ NAA induced PLB formation on the species studied here, but it seems to depend on the organism, for example Nayak et al. (2002) got 68\% PLB using $22 \mu \mathrm{M}$ BAP and $2.7 \mu \mathrm{M}$ NAA on Cymbidium aloifolium. On the other hand, Tokuhara and Mii (2001) induced PLB formation of Phalaenopsis in $0.5 \mu \mathrm{M}$ NAA. The increased response in growing seedlings and PLB formation with organic supplements such as potato

Fig. 3. Effects of growth regulators BAP/ANA and organic supplements on explants: a) elongation and enlargement on M5 medium, b) PLB formation on M7 medium, c) plantlet on M6 medium and, d) proliferation on M8 medium. Scale bar $5 \mathrm{~mm}$. 
starch, is probably due to the starch richness in phosphate sterified glucose polymers, as well as its niacin and thiamine contents and in minor proportion, its lysophospholipid and protein contents (Arditti and Ernst, 1984; Islam et al., 2000; Penfield and Campbell, 1990) resulting in an increased protocorm size, PLB formation and plants from basal buds. Coconut water is a common supplement in orchid micropropagation due its macronutrient and auxin content, which favored the formation of entire L. albida plants (Arditti and Ernest, 1993; Islam et al., 2000).

Finally, these results establish a guideline toward ex situ conservation proposals, which can be applied in seed banks and tissue culture laboratories for the preservation and regeneration of PLB and production of in vitro plantlets. Tissue culture can provide plant germplasm for regional preservation efforts and may help as a useful alternative for a sustainable management program. This in turn will diminish pressure over wild populations of the Zapotitlan Salinas Valley and encourage at the same time, vegetative propagation and other horticultural tasks, thus contributing to the conservation of this both naturally and culturally valuable plant resource.

\section{Literature Cited}

Arditti, J. and R. Ernst. 1984. Physiology of germinating orchid seeds, p. 177-222. In: J. Arditti (ed.).
Orchid biology: Reviews and perspectives, III. Cornell Univ. Press, Ithaca, N.Y.

Arditti, J. and R. Ernst. 1993. Micropropagation of orchids. Wiley, New.York.

Halbinger, F. and M.A. Soto. 1997. Laelias de México.Asociación Mexicana de Orquideología A.C. México D.F.

Harrison, C.R. and J. Arditti. 1978. Physiological changes during the germination of Cattleya aurantiaca (Orchidaceae). Bot. Gaz. 139:180-189.

Islam, M.O., S. Matsui, and S. Ichihashi. 2000. Effects of complex organic additives on seed germination and carotenoid content in Cattleya seedlings. Lindleyana 15:81-88.

Linington, H.S. and W.H. Pritchard. 2000. Gene banks. In: S. Levin (ed.). Encyclopedia of biodiversity. Academic Press New York.

Nayak, R.N., S. Sahoo., S. Patnaik, and S.P. Rath. 2002. Establishment of thin cross section (TCS) culture method for rapid micropropagation of Cymbidium aloifolium (L.) Sw. and Dendrobium nobile Lindl. (Orchidaceae). Sci. Hort. 94:107-116.

Mugambi, G. 2002. Research on Kenyan orchid seeds. Samara Intern. Nwsl. Part. Millenn. Seed Bank Proj. 2:17.

Ortíz, M.M. V. 2001. Viabilidad de las semillas de tres especies de orquídeas del Valle de Tehuacán, Puebla, bajo condiciones de almacenamiento. thesis. FES-Iztacala, UNAM.

Penfield, M.J. and A.M. Campbell. 1990. Experimental food science, p. 368. Academic Press, San Diego.

Pierik, R.L.M., P.A. Sprenkels., B. van der Harst, and Q.C. van der Meys. 1988. Seed germina- tion and further development of plantlets of Paphiopedilium ciliolare Pfitz, in vitro. Sci. Hort. 34:139-153.

Santos-Hernández, L. 2002. Estimación de la variabilidad genética de la orquídea Laelia albida en el valle de Zapotitlán de las Salinas, Puebla. thesis. FES-Iztacala, UNAM.

Seaton, P.T. and N.S.J. Hailes. 1989. Effect of temperature and moisture content on the viability of Cattleya aurantiaca seed, p .17-19. In: H.W. Pritchard (ed.). Modern methods in orchid conservation: The role of physiology ecology and management. Cambridge Univ. Press.

Seaton, P.T. and Pritchard, H.W. 2003. Orchid germplasm collection, storage and exchange, $\mathrm{p}$. 227-258. In: K.W. Dixon, S.P. Kell, R.L. Barrett, and P.J. Cribb (eds.). Orchid conservation. Natural History Publ., Kota Kinabalu, Sabah.

Shoushtari, B.D., R. Heydari, G.L. Johnson and J. Arditti. 1994. Germination and viability staining of orchid seeds following prolonged storage. Lindleyana. 9: 77-84.

Tokuhara, K. and M. Mii. 2001. Induction of embryogenic callus and cell suspension cultures from shoot tips excised from flower stalk buds of Phalaenopsis (Orchidaceae). In Vitro Cell. 37:457-461.

van Waes, J.M. and P.C. Debergh. 1986. Adaptation of the tetrazolium method for testing the seed viability, and scanning electron microscopy study of some Western European orchids. Plant Physiol. 66:435-442.

Vujanovic, V., M. ST-Arnaud., D. Barabé, and G. Thibeault. 2000. Viability testing of orchid seed and the promotion of colorations and germination. Ann. Bot. 86:79-86. 